\title{
RECURSOS DIGITAIS E PEDAGÓGICOS: BANCO INTERNACIONAL DE OBJETOS EDUCACIONAIS (BIOE) E PORTAL DO PROFESSOR BUSCANDO APRIMORAR O USO DA INFORMATICA NA EDUCAÇÃO
}

\author{
Paloma Alinne Alves RODRIGUES ${ }^{1}$ \\ Klaus SCHLÜNZEN JÚNIOR ${ }^{2}$ \\ Elisa Tomoe Moriya SCHLÜNZEN ${ }^{3}$
}

\begin{abstract}
RESUMO: Para aprimorar o uso da Informática na Educação, no ano de 2008, o Ministério da Educação (MEC), em parceria com instituições educacionais, criou o repositório educacional virtual intitulado: Banco Internacional de Objetos Educacionais (BIOE) e também o portal educacional: Portal do Professor. Entretanto, analisando o atual contexto educacional, observa-se que muitos professores ainda não estão devidamente capacitados para usarem a informática no cotidiano escolar. Desta forma, estas duas iniciativas do Ministério da Educação (MEC), possuem como principal intuito propiciar mudanças no paradigma do processo de uso da Informática na Educação. O repositório educacional BIOE é um recurso digital pedagógico que almeja viabilizar, por meio da disponibilização de Objetos Educacionais (OE), uma maneira diferenciada para trabalhar o processo de ensinoaprendizagem no cotidiano escolar. E o Portal do Professor, é um portal educacional voltado para o público docente, que almeja corroborar para a formação continuada do docente. Portanto, o presente artigo visa expor as duas iniciativas, supracitadas.
\end{abstract}

PALAVRAS-CHAVE: Informática na educação. Banco Internacional de Objetos Educacionais (BIOE). Portal do professor.

\section{Introdução}

Com a invenção dos primeiros computadores, a sociedade incorporou uma ferramenta tecnológica que possui um grande potencial e que começou a ser usada em diversos ramos. Devido ao grande uso do micro-computador, no final do século XX, iniciaram-se diversas pesquisas voltadas para a sua utilização no contexto educacional.

Atualmente, a sociedade do conhecimento, como é denominada por diversos autores, utiliza o computador para trabalhar, ter lazer, adquirir informação, para uso domestico e para obter conhecimento. E no contexto educacional, não poderia ser diferente, pois por meio dos

\footnotetext{
${ }^{1}$ Licenciada em Física. UNESP - Universidade Estadual Paulista. Faculdade de Ciências e Tecnologia Departamento de Física, Química e Biologia. Presidente Prudente - SP - Brasil. 19060-900 palomaraap@gmail.com

${ }^{2}$ UNESP - Universidade Estadual Paulista. Faculdade de Ciências e Tecnologia - Departamento de Matemática, Estatística e Computação. Presidente Prudente - SP - 19060-900 - klaus@fct.unesp.br

${ }^{3}$ UNESP - Universidade Estadual Paulista. Faculdade de Ciências e Tecnologia - Departamento de Matemática, Estatística e Computação. Presidente Prudente - SP - 19060-900 - elisa@fct.unesp.br
} 
recursos que o computador disponibiliza aos seus usuários, as atividades pedagógicas também podem ser realizadas, buscando aprimorar e auxiliar a construção do conhecimento.

Desta forma, destacamos o uso do computador na educação que busca agilizar as diversas atividades que podem ser realizadas ao longo do dia-a-dia escolar.

Pais (2008, p.29) afirma que

[...]A inserção dos recursos tecnológicos da informática na educação escolar pode contribuir para a melhoria das condições de acesso à informação, minimiza restrições relacionadas ao tempo e ao espaço e permite agilizar a comunicação entre professores, alunos e instituições. Além disso, torna-se possível trabalhar com softwares específicos para cada disciplina.

Entretanto, a Informática na Educação, é um processo que ocorre em diversos países, mesmo que seja de forma desigual. Sabemos que no Brasil, uma grande parcela das escolas possui salas de informática, mas infelizmente poucas vezes estas são utilizadas devido à falta de recursos técnicos e humanos.

Mesmo assim, é primordial que os alunos tenham acesso a essa nova ferramenta, pois a escola é um ambiente que possui o dever de preparar os alunos para as diversas atividades profissionais presentes em um futuro cada vez mais próximo.

Além da escola, é fundamental que o professor esteja engajado em trabalhar com esta nova ferramenta, pois segundo Valente (1991) para que haja efetivamente o uso da Informática na Educação se fazem necessários quatro elementos fundamentais: o computador, o software educacional, o aluno e o professor.

Sendo que se torna primordial, que o professor seja participativo e esteja disposto a adquirir novos conhecimentos, sendo eles atualmente, conhecimentos tecnológicos.

Com a inserção da Informática na Educação, é imprescindível que o professor assuma o papel de mediador na construção do conhecimento do aluno. E desta forma, “[...] se em um passado recente o professor exercia um papel de centralizador como a principal fonte de informações para o aluno, hoje, com a ampliação das redes digitais, sua prática sofre uma ampliação considerável [...]” como argumenta Pais (2008, p.22-23).

Assim, o processo de ensino não possui mais, um caráter instrucionista, no qual o professor detinha todo o conhecimento, mas começa a ser construcionista, ou seja, o professor passará a ser um mediador na construção do conhecimento.

Destacando, que outro elemento fundamental, citado por Valente (1991) para o processo de inserção da Informática na Educação, é o software educacional, ou seja, o Objeto Educacional (OE), que segundo Tarauco, Fabre e Tamusiunas (2003) “[...] podem ser 
definidos como qualquer recurso, suplementar ao processo de aprendizagem, que pode ser reusado para apoiar a aprendizagem”.

Desta forma, deseja-se salientar que o computador sozinho não faz nada, apenas é uma máquina tecnológica e como a maioria das máquinas, necessita de alguns recursos para funcionar com total eficiência, desta forma, os OE, possuem o caráter de auxiliar o processo de ensino-aprendizagem, por meio da utilização do computador.

Mas, infelizmente, assim como o uso do computador na Educação é algo que o professor, ainda possui certas dificuldades, a busca e utilização dos OE se tornam ainda mais difícil.

Além disso, a internet disponibiliza diversas informações e recursos que não são devidamente selecionados, pelo professor e que em muitos casos não possuem caráter pedagógico para serem usados em sala de aula ou nos laboratórios de informática.

Diante deste exposto, no ano de 2008 o Ministério da Educação (MEC) em parceria com diversas instituições, lançou e inaugurou o repositório educacional do Banco Internacional de Objetos Educacionais (BIOE). Sendo que, este ambiente digital pedagógico é exclusivamente voltado para a comunidade educacional, visando auxiliar o professor na busca por OE para que os mesmos venham a ser utilizados em sala de aula ou nos laboratórios de informática.

Além deste repositório educacional, o Ministério da Educação (MEC), paralelamente ao lançamento do BIOE, lançou e inaugurou em 2008, o Portal do Professor. Tendo por objetivo, auxiliar os diversos educadores em seu cotidiano educacional, disponibilizando assim, diversos recursos digitais voltados para a comunidade educacional.

Entretanto, estaremos abordando estes dois assuntos, mais adiante, sendo que, inicialmente faremos um breve exposto sobre o professor e o uso da Informática na Educação.

\section{O professor e a informatica na educação}

O processo de inserção da Informática aplicada a Educação, para ser sustentável, exige que os professores sejam altamente motivados e que possam estar engajados com esta nova ferramenta pedagógica. Além disso, se faz referencia às Universidades, pois as mesmas poderiam oferecer cursos específicos ou disciplinas, voltadas para a Educação e Tecnologia, além de tantas outras maneiras de aprimorar este processo de inserção.

Mas, infelizmente o que acontece atualmente, é muito avesso ao que seria ideal ao processo de inserção tecnológica na Educação. Atualmente, o que enxergamos são iniciativas 
dos governos em disponibilizar materiais tecnológicos, como computadores, scanner, impressoras, projetores multimídias entre outros recursos.

Mas, é evidente que todos esses recursos tecnológicos são importantes, mas são insuficientes, pois do que adianta adquiri-los, sendo que a maior parte dos professores não recebe devida capacitação para utilizá-los, em seus cotidianos educacionais. E desta forma, muitos não podem proporcionar aos seus alunos aulas diferenciadas e dinâmicas.

Portanto, o que encontramos, no cenário atual, é uma variedade de professores desmotivados e que encontram muitas dificuldades em lidar com esses novos recursos tecnológicos.

Devido a este fato, é fundamental que os diversos profissionais ligados a Educação, possam receber cursos de capacitação para compreender a finalidade da tecnologia aplicada à Educação, pois desta forma, eles poderão inovar as suas práticas pedagógicas e terão a oportunidade de proporcionar aos seus alunos, diversas aulas com maior valor e significado pedagógico.

Além disso, é muito importante que o professor tenha o conhecimento, que ensinar por meio do uso do computador, exige uma nova metodologia, diferente do modelo tradicional baseado na utilização do livro e anotações.

Desse modo, o professor por meio do uso dos recursos tecnológicos, assim como afirma Valente (1999), estará exercendo o seu papel de mediador na construção do conhecimento dos seus alunos, e não estará apenas transmitindo informações, mas auxiliando o aluno na construção do seu próprio conhecimento.

Mas, infelizmente, ainda encontramos professores que estão contrários ao uso da informática aplicada à Educação, assim como afirma Area (2006, p.168):

Os professores pertencem a um grupo que por sua idade, foi alfabetizado culturalmente na tecnologia e formas culturais impressas. A palavra escrita, pensamento academicamente textualizado, o cheiro de papel, a biblioteca como cenários do saber foram, e são, para uma imensa maioria de professores, o único hábitat da cultura e do conhecimento.

Devido a este conjunto de fatores, se faz necessário que mesmo que, haja professores contrários, talvez devido ao medo, ou pela tecnofobia a máquina, como afirma Area (2006), ou principalmente devido à falta de cursos de capacitação em determinadas unidades escolares é fundamental que o professor busque alternativas para adquirir novos conhecimentos relacionados ao uso da Informática na Educação, pois os alunos necessitam 
estar preparados para aturem na sociedade do conhecimento, e não poderão estar aptos se os professores não estiverem preparados para auxiliá-los neste caminho de construção.

Diante deste exposto, para aprimorar processo de inserção da Informática na Educação, e auxiliar o professor na busca por Objetos Educacionais (OE), para serem utilizados em sala de aula ou em laboratório de informática, o Ministério da Educação (MEC) desenvolveu o repositório educacional do Bando Internacional de Objetos Educacionais (BIOE).

Sendo que a finalidade de um repositório educacional é a de armazenar qualquer recurso digital pedagógico com a finalidade de aplicação em ambientes de aprendizagem. Como exemplos de OE, estaremos citamos: animações, simulações, textos, mapas, experimentos, vídeos e hipertextos, entre outros (NASCIMENTO, 2009, p.352).

\section{Banco Internacional de Objetos Educacionais (BIOE)}

Com o intuito de auxiliar, os inúmeros profissionais ligados à Educação, no processo de busca por novos recursos digitais e a ter acesso aos diversos Objetos Educacionais (OE) que se encontram espalhados pelas redes digitais como a Internet.

No ano de 2008 o Ministério da Educação (MEC) em parceria com o Ministério da Ciência e Tecnologia, a Rede Latino-americana de Portais Educacionais (RELPE), a Organização dos Estados Ibero-americanos (OEI) e outras instituições, desenvolveu e lançou nacionalmente o repositório educacional do Banco Internacional de Objetos Educacionais (BIOE), conforme ilustra a figura 1:

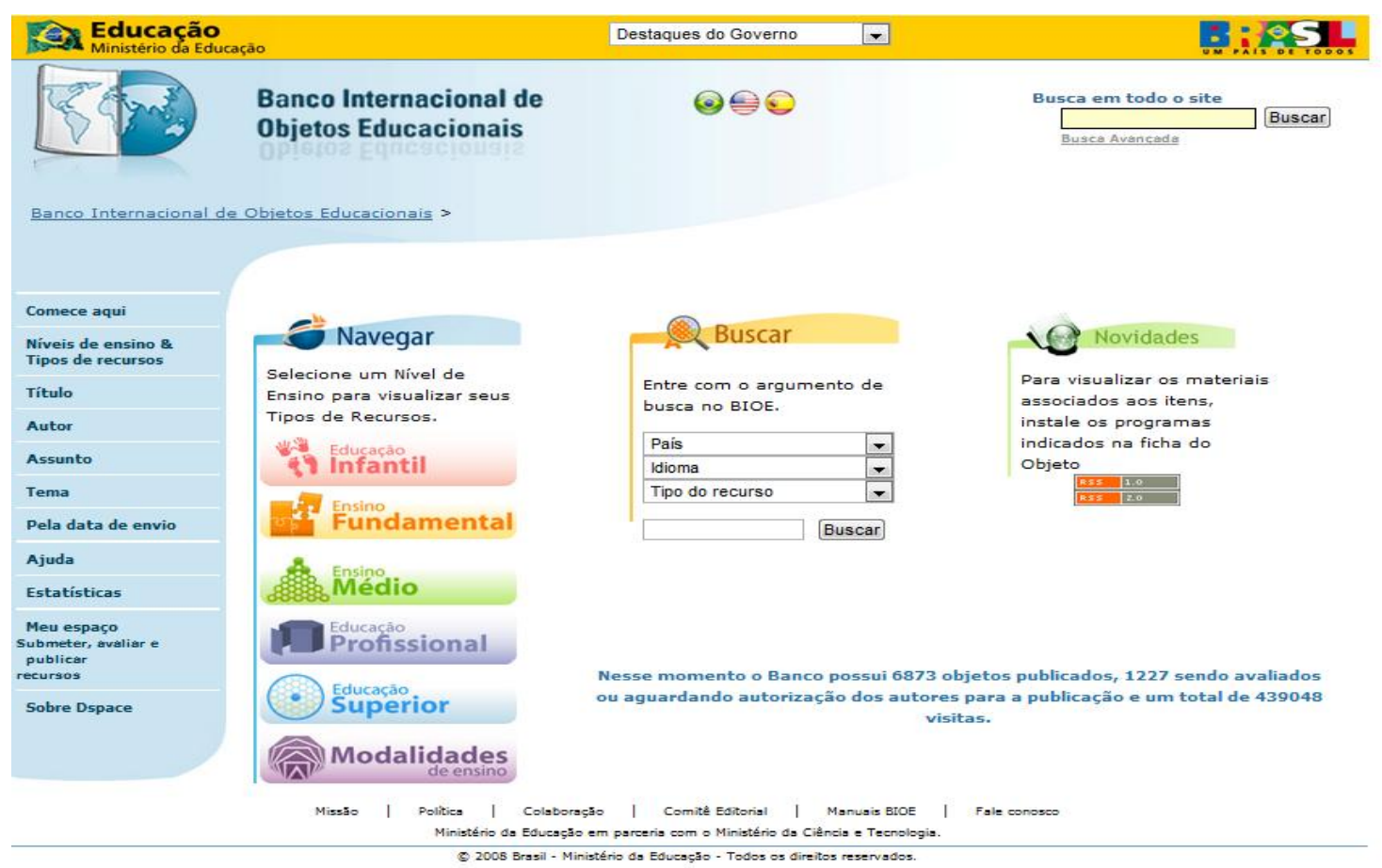


Figura 1 - Tela principal do Banco Internacional de Objetos Educacionais (BIOE) ${ }^{4}$.

Fonte: BRASIL (2009a).

Esse repositório possui diversos OE como, por exemplo, simulação, animação, vídeos, softwares educativos, experimentos práticos, mapas, hipertextos e áudios.

Entretanto, para disponibilizar Objetos Educacionais no repositório do BIOE, o Ministério da Educação (MEC), conta com a participação de seis Universidades Públicas e Federais, espalhadas pelo território brasileiro. Entretanto, neste trabalho destaca-se a equipe da Universidade Estadual Paulista - Faculdade de Ciências e Tecnologia (FCT/UNESP), no campus de Presidente Prudente.

Sendo que durante o ano de 2008, a equipe da FCT/UNESP trabalhava as seguintes áreas do conhecimento: Física, Química, Matemática, Engenharia Ambiental, Educação Especial e Geografia, e no ano de 2009, possui mais duas equipes de tradutores da língua Inglesa e Espanhola. Contudo, neste momento almeja-se destacar o processo de investigação, seleção e catalogação dos OE, para que os mesmos possam ser disponibilizados no BIOE e desta forma, que venham a auxiliar os professores em seus processos de buscas pela Internet.

O processo de investigação, seleção e catalogação seguem procedimentos préestabelecidos pelo Ministério da Educação (MEC).

Sendo que, inicialmente realizam-se buscas e pesquisas em sites, nacionais e internacionais, por todo o mundo. Em seguida, analisa-se o conteúdo pedagógico do $\mathrm{OE}$ para verificar se o mesmo possui relevância significativa e se, principalmente está de acordo com os Parâmetros Curriculares Nacionais (PCN), pois somente desta forma, ele poderá ser utilizado como um complemento educacional, durante as aulas ministradas pelo professore na sala de aula ou em laboratórios de informática.

Após, o processo de análise busca-se o contato com os autores dos respectivos OE, por meio de e-mail e telefonemas, desejando-se solicitar a autorização deles, para que o recurso possa ser devidamente publicado no repositório educacional do BIOE.

Com a devida autorização do autor, realiza-se a descrição e uma avaliação criteriosa do OE, por meio de um formulário elaborado pela equipe de avaliadores da FCT/UNESP. Entretanto, para que o OE venha a ser devidamente submetido no repositório educacional do BIOE, a descrição e o OE são enviados para a Comissão Avaliadora do MEC.

\footnotetext{
${ }^{4}$ Imagem retirada do site <https://objetoseducacionais.mec.gov.br> no dia 17 ago. 2009.
} 
Finalmente, após a avaliação da Comissão Avaliadora, ocorre à liberação por parte do avaliador local, que se encontra no campus da FCT/UNESP. Portanto, após a liberação o OE torna-se disponível para todos os professores utilizarem em seu cotidiano educacional.

Atualmente, o repositório educacional do BIOE, disponibiliza para a comunidade educacional, cerca de $6873^{5} \mathrm{OE}$, para serem utilizados pelos professores durante as suas aulas com os alunos.

Desta forma, o repositório educacional do BIOE é mais uma ferramenta digital pedagógica que visa aprimorar a inserção da Informática na Educação, pois por meio desses OE os professores poderão utilizar diversas ferramentas digitais, diferentes em seu cotidiano escolar, proporcionando desta forma, uma aula diferenciada e dinâmica, buscando promover a construção do conhecimento dos seus alunos.

Ainda, visando proporcionar aos professores novos recursos digitais pedagógicos, o Ministério da Educação (MEC), lançou um portal direcionado para o público docente, almejando disponibilizar diversas alternativas para aprimorar a formação continuada desses docentes.

\section{Portal do professor}

Paralelamente, a inauguração do BIOE, em 2008 o Ministério da Educação (MEC) lançou e inaugurou o Portal do Professor, almejando corroborar o processo de inserção da Informática na Educação.Por meio, deste novo ambiente digital, os diversos profissionais ligados a Educação poderão encontrar novos recursos que poderão auxilia-los em sua formação continuada, conforme pode ser observado na figura 2.

\footnotetext{
${ }^{5}$ Quantidade de OE, retirados do site <https://objetoseducacionais.mec.gov.br> , no dia 17 ago. 2009
} 


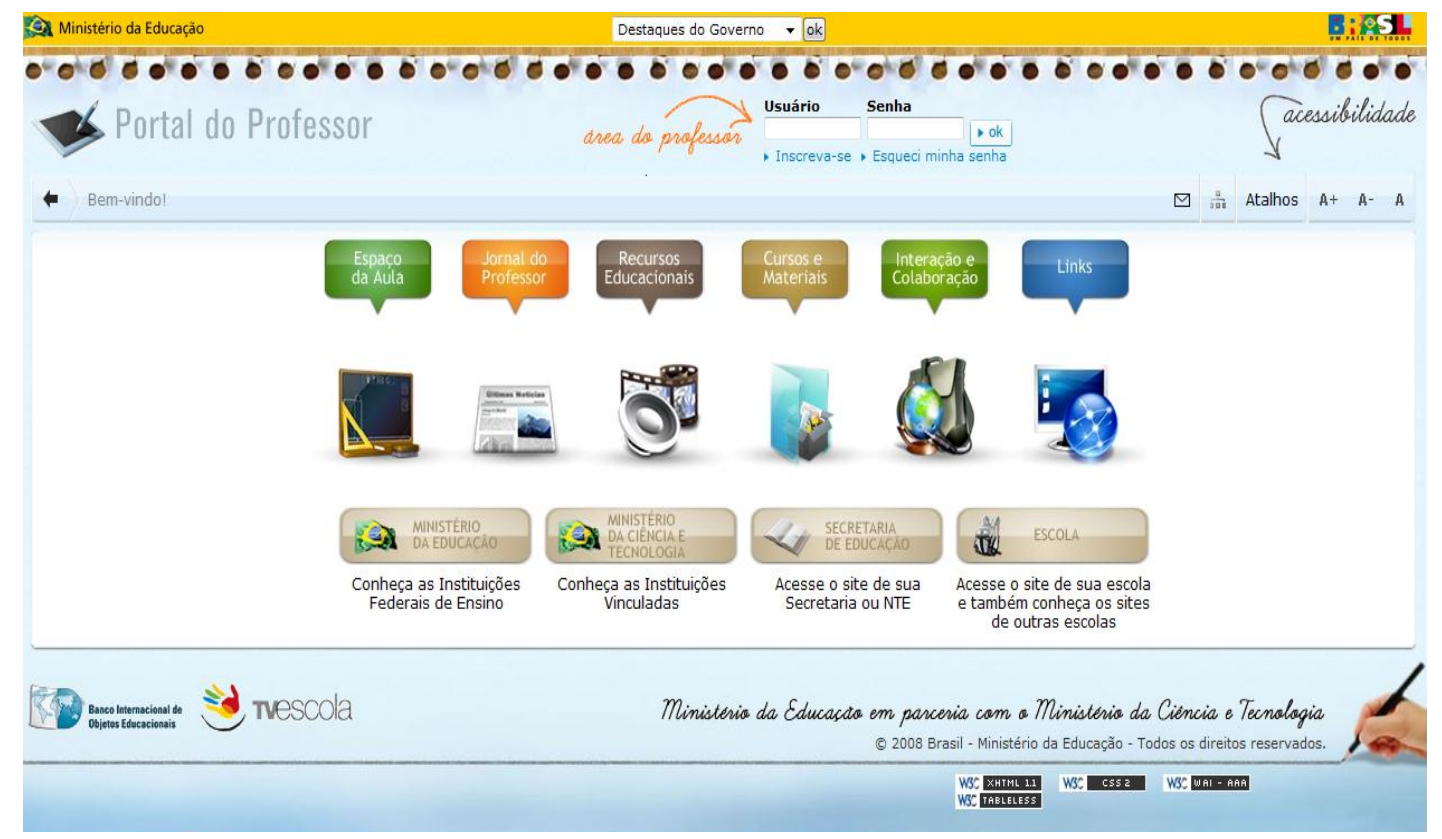

Figura 2 - Tela Principal do Portal do Professor ${ }^{6}$

Fonte: BRASIL (2009b).

O Portal do Professor disponibiliza diferentes possibilidades para que o professor possa usar diferentes recursos que venha a complementar a sua prática por meio da Informática na Educação.

Com este intuito o Portal do Professor pode integrar os professores nesta nova realidade, de forma a unificar a política de qualificação de infra-estrutura das diversas escolas públicas em todo o Brasil. Por meio, deste novo ambiente virtual pedagógico o professor tem disponível, seis recursos que podem auxiliar diferentes atividades na sua comunidade escolar, como, por exemplo,o espaço de aula, onde o professor poderá encontrar diversas aulas elaboradas, por diversos outros profissionais, que utilizam diversos OE, além disso, o próprio professor poderá criar aulas e torna-las disponível para outros professores.

O Jornal do Professor é um espaço informativo que retrata quinzenalmente, temas relacionados com a Educação, logo, este veículo proporciona ao professor informações sobre o cotidiano escolar de diferentes regiões do país. O espaço de Recursos Educacionais é um recurso que disponibiliza diversos tipos de OE como, por exemplo: simulação, animação, vídeos, experimentos práticos, mapas, entre outros, e desta forma, o professor poderá criar diversas aulas utilizando estes OE.

Um outro espaço muito importante, dentro deste Portal é o espaço de Cursos e Materiais, pois busca disponibilizar diversos cursos e materiais para aprimorar e subsidiar a

\footnotetext{
${ }^{6}$ Imagem retirada do site <http://portaldoprofessor.mec.gov.br./index.html?> no dia 17 ago. 2009.
} 
formação dos professores. O ambiente de Interação e Colaboração, é um espaço onde os professores podem interagir por meio de chat, blog, fórum entre outros. Por ultimo destacamos o espaço de Links, pois este disponibiliza diversos sites e portais (nacionais e internacionais) que possuem também como objetivo auxiliar a formação dos professores.

Diante da diversidade de recursos disponíveis, tanto no BIOE quanto no Portal do Professor, vale ressaltar que as duas iniciativas do MEC visam contribuir para a mudança do paradigma educacional, acoplando a informática na Educação.

\section{Considerações finais}

A partir do exposto, podemos concluir que o processo de uso da Informática na Educação, é um novo processo que visa auxiliar e aprimorar o processo de ensinoaprendizagem. Entretanto, mesmo que haja uma parcela de professores que sentem dificuldades mediante a este novo processo, é necessário que esses professores busquem novas alternativas para obter conhecimentos relacionados ao uso de recursos tecnológicos na Educação, e em especial destaca-se o computador.

Os dois novos projetos, BIOE e o Portal do Professor, que foram desenvolvidos pelo Ministério da Educação (MEC) visam auxiliar esse os diversos professores, que encontram dificuldades com relação ao uso da Informática na Educação.

Desta forma, como são recursos que proporcionam fácil acesso, e que auxiliam o processo de ensino-aprendizagem, consequentemente, pode e devem ser inseridos pedagogicamente e didaticamente em atividades disciplinares ou interdisciplinares.

No entanto, diante da diversidade de novos recursos digitais pedagógicos, que estão sendo disponibilizados, se faz necessário que o professor receba uma formação adequada para atuar com estes novos recursos digitais pedagógicos, sendo estimulado a trabalhar com esta nova prática, para que o processo educacional possa realmente ser renovado e aprimorado.

\section{COMPUTING IN EDUCATION: INTERNATIONAL BASE OF EDUCATIONAL OBJECTS AND THE TEACHER'S PORTAL OF THE MINISTRY OF EDUCATION (MEC)}

ABSTRACT: To improve the use of Computing in Education, in the year of 2008, the Ministry of Education (MEC), in partnership with educational institutions, created the virtual educational repository entitled: "Banco Internacional de Objetos Educacionais (BIOE)" (International Base of Educational Objects), and also the educational portal: Teacher's Portal. However, analyzing the actual educational context, it is observed that many teachers are not yet properly capable of using computing in the scholar quotidian. Due to this, these 
two initiatives of the Ministry of Education (MEC), have as their main purpose, to produce changes in the paradigm of the process of Computing usage in Education. The educational repository $B I O E$ is a pedagogic digital resource which aims to make possible, through the disposal of Educational Objects (OE), a different way to work the process of teachinglearning in the scholar quotidian. And the Teacher's Portal, is an educational portal recommended to teachers, who aims to corroborate to the continued formation of the teacher. So, this article aims to expose two initiatives, mentioned above.

KEYWORDS: Computing in education. BIOE - (International Base of Educational Objects). Teacher's portal.

\section{REFERÊNCIAS}

AREA, M. Vinte anos de políticas institucionais para incorporar as tecnologias da informação e comunicação ao sistema escolar. In:SANCHO, J. M; HERNÁNDEZ, F. Tecnologias para transformar a educação. Porto Alegre: Artmed, 2006. p.153-175.

BRASIL. Ministério da Educação. Secretaria de Educação a Distância. Banco

Internacional de Objetos Educacionais. 2009a. Disponível em:

$<$ https://objetoseducacionais.mec.gov.br>. Acesso em: 17 ago. 2009.

Ministério da Educação. Secretaria de Educação a Distância. Portal do Professor. 2009b. Disponível em: <http://portaldoprofessor.mec.gov.br./index.html>. Acesso em: 17 ago. 2009.

NASCIMENTO, A. C. A. A. Aprendizagem por meio de repositórios digitais e virtuais. In: LITTO F. M.; FORMIGA, M. Educação a distância: o estado da arte, 2009. p.352-357.

PAIS, L.C. Educação escolar e as tecnologias da informática. Belo Horizonte: Autentica, 2008.

TAROUCO, L. M. R.; FABRE, M.C.J.M; TAMUSIUNAS, F.R. Reusabilidade de objetos educacionais. Disponível em:

<http://www.cinted.ufrgs.br/renote/fev2003/artigos/marie_reusabilidade.pdf>

Acesso em: 14 ago. 2009

VALENTE, J. A. (Org.). O computador na sociedade do conhecimento. Campinas: Ed. da Unicamp, 1999.

Liberando a mente: computadores na educação especial. Campinas: Ed. da

Unicamp, 1991. 